Research Article

Check for updates

OPEN ACCESS

Received: May 15, 2019

Accepted: Nov 25, 2019

*Correspondence:

Sangchul Roh

Department of Occupational and

Environmental Medicine, Dankook University

Hospital, 119 Dandae-ro, Dongnam-gu,

Cheonan 31116, Korea.

E-mail: scroh@dku.edu

Copyright (c) 2019 Korean Society of

Occupational \& Environmental Medicine

This is an Open Access article distributed

under the terms of the Creative Commons

Attribution Non-Commercial License (https://

creativecommons.org/licenses/by-nc/4.0/)

which permits unrestricted non-commercial

use, distribution, and reproduction in any

medium, provided the original work is properly

cited.

ORCID iDs

Jihyun Shin (D)

https://orcid.org/0000-0002-7322-5580

Sangchul Roh (D)

https://orcid.org/0000-0003-4467-5416

Abbreviations

PPE: personal protective equipment; OR: odds

ratio; $\mathrm{Cl}$ : confidence interval; SD: standard

deviation.

Funding

This work was supported by the Ministry of

Agriculture, Food and Rural Affairs of the

Republic of Korea

Competing interests

The authors declare that they have no

competing interest.

\section{A study of risk factors for the possible cases of acute occupational pesticide poisoning of orchard farmers in some parts of south Chungcheong province}

\author{
Jihyun Shin (1) and Sangchul Roh (i) *
}

Department of Occupational and Environmental Medicine, Dankook University Hospital, Cheonan, Korea

\begin{abstract}
Background: The objective of the present study is to identify differences in the prevalence of acute occupational pesticide poisoning across Korean orchard farmers' farming characteristics and the risk factors that have an effect on acute occupational pesticide poisoning. Methods: For 3 years $(2014,2015$, and 2017), a questionnaire survey was conducted on 394 orchard farmers in some parts of south Chungcheong Province in relation to pesticide poisoning. 323 orchard farmers who responded to acute occupational pesticide poisoning were included for final analysis. With acute occupational pesticide poisoning as the dependent variable, a $\chi^{2}$ test and a multiple logistic regression analysis were conducted. Results: The results of the prevalence of acute occupational pesticide poisoning across farming characteristics showed that the group wearing 4 or more pesticide personal protective equipment (PPE) had a lower prevalence of acute occupational pesticide poisoning than the group wearing 3 or less pesticide PPE $(p<0.05)$. Furthermore, an analysis by area of fruit farming revealed that the group with more than $12,000 \mathrm{~m}^{2}$ in the area of fruit farming had a higher prevalence of acute occupational pesticide poisoning $(p<0.05)$. Orchard farmers mainly use a speed sprayer to spray pesticides, and the speed sprayer can be categorized by presence of cabin. The analysis of the prevalence of acute occupational pesticide poisoning by speed sprayer's cabin existence found that existence of speed sprayer's cabin did not show a statistically significant difference in the prevalence of acute occupational pesticide poisoning.

Conclusions: The present study analyzed the prevalence of acute occupational pesticide poisoning depending on the speed sprayer's cabin existence and found no significant difference. The fact that famers using the cabinless style speed sprayer shows a higher percentage in wearing PPE than those using the cabin style speed sprayer is suggested to elucidate the result. As the first study in Korea which examined the prevalence of acute occupational pesticide poisoning by speed sprayer's cabin existence, the present study proposes the expected effect that increase of wearing pesticide PPE along with employ of speed sprayer's cabin can reduce the prevalence of acute occupational pesticide poisoning among orchard farmers.
\end{abstract}

Keywords: Acute occupational pesticide poisoning; Orchard; Speed sprayer; Personal protective equipment 
Authors contributions

Conceptualization: Shin J; Data curation: Shin J; Formal analysis: Shin J; Funding acquisition: Roh S; Investigation: Roh S; Methodology: Shin J; Project administration: Roh S; Resources: Roh S; Software: Shin J; Supervision: Roh S; Validation: Shin J; Visualization: Shin J; Writing - original draft: Shin J; Writing - review \& editing: Roh S

\section{INTRODUCTION}

Pesticides are substances that protect crops from weeds, diseases, and pests and help crops to grow [1], increase quantitative productivity in agriculture, and reduce the time and manpower put into farming. In today's agriculture that requires a high level of productivity, pesticides have established themselves as an indispensable choice. There are study findings, however, that pesticides used to remove weeds, diseases, and pests could be harmful to not only animals but also humans [2-7]. In particular, studies reported that when humans are exposed to pesticides, the pesticides can cause cancer [8-13], contact dermatitis [14-16], autoimmune disease [17], neurotoxicity [18-21], ocular disease [22], and diabetes mellitus $[23,24]$. In this regard, since farmers have risk of frequent exposure to a high level of pesticides during farming, it is believed to pose a hazardous health risk.

Given Korea's total farm area by type of farming in 2017, the area of fruit farming is larger than that of food crop (rice, wheat and barley, miscellaneous grains, legumes, and root and tuber crops) and vegetable farming [25]. In addition, according to a study on the status of pesticide use by type of crop, fruit farming uses more pesticides per unit area than vegetable and rice farming [26]. The above findings suggest that orchard farmers have a larger farm area and use more pesticides per unit area. Furthermore, a previous study showed a higher prevalence of acute occupational pesticide poisoning among orchard farmers than those cultivating other crops [27].

Currently, statistics on pesticide poisoning in Korea are mostly about patients who visited the emergency room due to pesticide intoxication, instead of the results of famers' occupational pesticide poisoning, and the cases often include taking in pesticides [28,29]. Furthermore, since acute occupational pesticide poisoning symptoms are often non-specific and mild, it seems that farmers are less likely to visit hospitals or clinics when they have the symptoms $[6,30]$, which seems to explain few study findings on farmers' acute occupational pesticide poisoning up to this day.

The present study aims to identify differences in orchard farmers' prevalence of acute occupational pesticide poisoning across farming characteristics and the risk factors that have an effect on acute occupational pesticide poisoning.

Orchard feature its usage of special machine known as a speed sprayer. When pesticide is sprayed, dermal exposure is the most common pathway known for pesticide exposure [31]. Therefore, in spite of using cabin-style speed sprayer, exposure to pesticide is feasible without wearing PPE. In addition, due to absence of past study which specifically classified of pesticide spraying method depending on presence of cabin, for the first time, present study examined acute occupational pesticide poisoning symptoms of speed sprayer depending on presence of cabin.

\section{METHODS}

\section{Study participants}

The present study examines famers in south Chungcheong Province from the 'Local Community Farmer Screening and Questionnaire Epidemiological Study' conducted from 2014 to 2017 by the Center for Farmers' Safety and Health in Dankook University Hospital. 
The one-on-one questionnaire survey was conducted for 3 years (2014, 2015, and 2017) on 394 orchard farmers in south Chungcheong Province (Yesan-gun, Nonsan, Cheonan, Dangjin, Gongju, Asan, Boryeong, and Hongseong-gun). The present study excluded 4 farmers no longer farm occupationally anymore and 1 farmer who did not respond to the acute pesticide poisoning question. Furthermore, the present study excluded 22 farmers who were suffering from 6 diseases (stroke, angina/myocardial infarction, chronic obstructive pulmonary disease, chronic renal failure, Parkinson's disease, and multiple peripheral neuropathy), which could potentially show symptoms similar to acute pesticide poisoning or whose drugs might delay the expression of acute pesticide poisoning symptoms by 48 hours. Administration of warfarins, superwarfarins and coumarins are exceptions since symptoms may be delayed greater than 48 hours [32]. Efficient metabolism of pesticide is difficult for patients with chronic renal failure, dyspnea may occur in farmers with chronic obstructive pulmonary disease, and Parkinson's disease and multiple peripheral neuropathy may cause paresthesia, paralysis, muscle weakness, which makes patient these diseases inappropriate candidate for this study.

Also, the present study excluded 44 farmers who do not use a speed sprayer. Hence, the present study included 323 participants for final analysis. In particular, 214 farmers $(66.3 \%)$ sprayed pesticides in person. Fig. 1 shows the above process in a flow chart.

\section{Study description and methods}

All questionnaire surveys were conducted by one-on-one interview by the researcher who fully understood the present study's purposes and completed research ethics training.

Questionnaire items included sociodemographic factors (gender, age, educational status, the presence of a spouse, annual income, etc.), farming occupational exposure factors (period of farming, frequency of spraying pesticides, types of crops, role in spraying pesticides, method
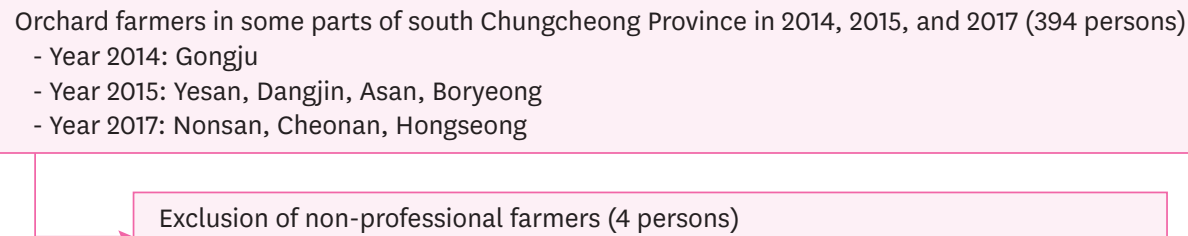

Exclusion of non-professional farmers (4 persons) Exclusion of non-respondents of acute pesticide addiction questionnaires (1 person)

Exclusion of sick farmers below (22 persons)

- Stroke

- Angina/myocardial infarction

- Chronic obstructive pulmonary disease

- Chronic renal failure

- Parkinson's disease

- Multiple peripheral neuropathy

\section{Exclusion of farmers who do not use a speed sprayer (44 persons)}

Orchard farmers in some parts of south Chungcheong Province in 2014, 2015, and 2017 (323 persons) Farmers spraying pesticide directly (214 persons)

Fig. 1. Flow chart of inclusion and exclusion of the study participants. 
of spraying pesticides, PPE, etc.), acute occupational pesticide poisoning symptoms, past disease history (stroke, angina/myocardial infarction, chronic renal failure, etc.), and lifestyle factors (exercise, alcohol, smoking, etc.). The questionnaire excluded cotton gloves, cotton shirt, and cotton mask from PPE. It was developed based on previous studies [32-34].

Using the same standards in previous studies [33-35], the present study defined 'acute occupational pesticide poisoning' as a case which the participant experienced at least 1 out of 21 clinical symptoms provided in the questionnaire within 48 hours after exposure to pesticides over the last 1 year. The 21 clinical symptoms included 'skin irritation, dizziness, nausea, fatigue, headache, eye irritation, vomiting, sore throat, chest pain, runny nose, excessive sweating, paresthesia, hyperactivity (anxiety), muscle weakness, lacrimation, diarrhea, dyspnea, blurred vision, slurred speech, paralysis, and syncope' [33-35]. Refer World Health Organization for information of symptoms of acute pesticide poisoning for each pesticide category [36]. For instance, acute occupational pesticide poisoning symptoms of organophosphorus and carbamate pesticide include dyspnea, vomiting, pupil contraction, epiphora, excessive sweating, and sialosis.

\section{Analysis method}

Differences between groups in acute occupational pesticide poisoning were analyzed using the $\chi^{2}$ test, $t$-test, and Mann-Whitney test. With acute occupational pesticide poisoning as the dependent variable, $\chi^{2}$ test was conducted by groups of gender, age, annual income, educational status, the presence of a spouse, smoking, alcohol, regular exercise, average sleeping time of last year, farming period, the cultivation of crops and fruits, total farm area, the area of fruit farming, role in spraying pesticide, spraying pesticide's frequency, speed sprayer's cabin existence, the number of PPE worn while spraying pesticide, PPE worn while spraying pesticide. With acute occupational pesticide poisoning as the dependent variable, analysis of t-test was conducted by age and Mann-Whitney test was executed by total farm area and the area of fruit farming. Also, with acute occupational pesticide poisoning as the dependent variable, a multiple logistic regression analysis was conducted by adjusting gender, age, educational status, smoking, and drinking status to examine the factors that had an effect on acute occupational pesticide poisoning symptoms. PPE was categorized into wearing (always) and not wearing (almost never, sometimes, and often), and compliance with safety guidelines was divided into compliance (always) and non-compliance (never, sometimes, and often).

The $p$-value of less than 0.05 was considered to indicate statistical significance. $\mathrm{R}$ (ver. 3.5.2; $\mathrm{R}$ Foundation, Vienna, Austria) was used for the statistical analysis of data.

\section{Ethics statement}

For the present study, we obtained approval from the Institutional Review Board of Dankook University Hospital (IRB No. 2014-08-003 \& IRB No. 2017-07-001) and received written consent for voluntary participation from every participant fully explained before participating.

\section{RESULTS}

\section{Prevalence by acute occupational pesticide poisoning symptom}

The acute occupational pesticide poisoning symptoms of farmers in south Chungcheong Province were surveyed with multiple responses allowed, and Table 1 provides the prevalence 
Table 1. The symptom prevalence of acute occupational pesticide poisoning using the analysis of multiple responses

\begin{tabular}{lccc}
\hline Symptom of acute occupational pesticide poisoning & Total $(\mathrm{n}=52)$ & Man $(\mathrm{n}=31)$ & Woman $(\mathrm{n}=21)$ \\
\hline Skin irritation & $20(38.5)$ & $10(32.3)$ & $10(47.6)$ \\
Dizziness & $15(28.8)$ & $9(29.0)$ & $6(28.6)$ \\
Nausea & $12(23.1)$ & $7(22.6)$ & $5(23.8)$ \\
Headache & $10(19.2)$ & $6(19.4)$ & $4(19.0)$ \\
Fatigue & $9(17.3)$ & $8(25.8)$ & $1(4.8)$ \\
Eye irritation & $7(13.5)$ & $4(12.9)$ & $3(14.3)$ \\
Vomiting & $3(5.8)$ & $3(9.7)$ & $0(0.0)$ \\
Sore throat & $3(5.8)$ & $3(9.7)$ & $0(0.0)$ \\
Runny nose & $3(5.8)$ & $1(3.2)$ & $2(9.5)$ \\
Chest pain & $2(3.8)$ & $2(6.5)$ & $0(0.0)$ \\
Excessive sweating & $2(3.8)$ & $2(6.5)$ & $0(0.0)$ \\
Paresthesia & $2(3.8)$ & $1(3.2)$ & $1(4.8)$ \\
Hyperactivity (anxiety) & $1(1.9)$ & $1(3.2)$ & $0(0.0)$ \\
Muscle weakness & $1(1.9)$ & $1(3.2)$ & $0(0.0)$ \\
Lacrimation & $0(0.0)$ & $0(0.0)$ & $0(0.0)$ \\
Diarrhea & $0(0.0)$ & $0(0.0)$ & $0(0.0)$ \\
Dyspnea & $0(0.0)$ & $0(0.0)$ & $0(0.0)$ \\
Blurred vision & $0(0.0)$ & $0(0.0)$ & $0(0.0)$ \\
Slurred speech & $0(0.0)$ & $0(0.0)$ & $0(0.0)$ \\
Paralysis & $0(0.0)$ & $0(0.0)$ & $0(0.0)$ \\
Syncope & $0(0.0)$ & $0(0.0)$ & $0(0.0)$ \\
\hline Values are express) &
\end{tabular}

Values are expressed as unweighted counts and estimated percentages number (\%).

of 21 clinical symptoms. Among 323 participants, 52 (16.1\%) experienced at least 1 acute occupational pesticide poisoning symptom within 48 hours after exposure to pesticides over the last 1 year. Among those 52, 31 were men and 21 were women. The average number of multiple responses from 52 who experienced acute occupational pesticide poisoning symptoms was $1.7 \pm 1.5$. The prevalence by symptom was in the order of 20 participants with skin irritation (38.5\%), 15 with dizziness (28.8\%), and 12 with nausea $(23.1 \%)$.

\section{Prevalence of acute occupational pesticide poisoning by participants' general demographic characteristics}

Table 2 shows the prevalence of acute occupational pesticide poisoning by general characteristics of the participants. The prevalence of acute occupational pesticide poisoning by general demographic factor except for age (gender, annual income, educational status, the presence of a spouse, smoking, alcohol, exercise, and sleeping time) showed no statistically significant difference.

According to a t-test analysis, the average age of the group whose members experienced acute occupational pesticide poisoning was $59.9 \pm 9.0$, which is lower than the average age of the group (63.7 \pm 7.6$)$ whose members didn't experience it, and this was statistically significant $(p<0.01)$.

\section{Comparison of the prevalence of acute occupational pesticide poisoning by characteristics of the agricultural environment}

Table 3 shows the results of an analysis of the prevalence of acute occupational pesticide poisoning by characteristics of the agricultural environment. An analysis of the prevalence of acute occupational pesticide poisoning by period of farming revealed that the group with less than 20 years in farming accounted for $27.7 \%$, which was the highest but not statistically significant. By total farm area, the participants were divided into 3 groups to analyze the prevalence of acute occupational pesticide poisoning. The results showed that the group with a larger total farm area had a higher prevalence of acute occupational pesticide poisoning, which was statistically significant $(p<0.05)$. The prevalence of acute occupational pesticide 
Table 2. The prevalence of acute occupational pesticide poisoning by general characteristics of the study participants $(n=323$ )

\begin{tabular}{|c|c|c|c|c|c|c|}
\hline \multirow[t]{2}{*}{ Variables } & \multirow[t]{2}{*}{ Total } & \multicolumn{2}{|c|}{ Acute pesticide poisoning } & \multirow[t]{2}{*}{$p$-value } & \multirow{2}{*}{$\begin{array}{l}\text { Crude OR } \\
(95 \% \mathrm{Cl})\end{array}$} & \multirow{2}{*}{$\begin{array}{l}\text { Adjusted OR }{ }^{a} \\
\quad(95 \% \mathrm{Cl})\end{array}$} \\
\hline & & No & Yes & & & \\
\hline Gender & & & & 0.63 & & \\
\hline Man & $202(62.5)$ & $171(84.7)$ & $31(15.3)$ & & 1 & 1 \\
\hline Woman & $121(37.5)$ & $100(82.6)$ & $21(17.4)$ & & $1.16(0.63-2.12)$ & $2.20(0.78-6.20)$ \\
\hline \multicolumn{7}{|l|}{ Age (years) } \\
\hline Mean \pm SD & $63.1 \pm 8.0$ & $63.7 \pm 7.6$ & $59.9 \pm 9.0$ & 0.00 & & \\
\hline$\geq 70$ & $64(21.3)$ & $57(89.1)$ & $7(10.9)$ & 0.71 & 1 & 1 \\
\hline $60-69$ & $164(50.8)$ & $141(86.0)$ & $23(14.0)$ & & $1.33(0.54-3.27)$ & $1.27(0.51-3.20)$ \\
\hline$<60$ & $95(29.4)$ & 73 (76.8) & $22(23.2)$ & & $2.45(0.98-6.15)$ & $2.16(0.82-5.70)$ \\
\hline Annual income (10,000 won) & & & & 0.11 & & \\
\hline$<3,000$ & $73(26.7)$ & $65(89.0)$ & $8(11.0)$ & & 1 & 1 \\
\hline $3,000-4,999$ & $78(28.6)$ & $70(89.7)$ & $8(10.3)$ & & $0.93(0.33-2.62)$ & $0.87(0.30-2.53)$ \\
\hline$\geq 5,000$ & 122 (44.7) & $98(80.3)$ & $24(19.7)$ & & $1.99(0.84-4.70)$ & $1.69(0.69-4.11)$ \\
\hline No answer & 50 & & & & & \\
\hline Educational status & & & & 0.42 & & \\
\hline$\leq$ Middle school & $216(67.3)$ & $184(85.2)$ & $32(14.8)$ & & 1 & 1 \\
\hline$\geq$ High school & $105(32.7)$ & $85(81.0)$ & $20(19.0)$ & & $1.35(0.73-2.50)$ & $1.17(0.59-2.32)$ \\
\hline No answer & 2 & & & & & \\
\hline The presence of a spouse & & & & 0.67 & & \\
\hline With a spouse & $312(96.9)$ & $262(84.0)$ & $50(16.0)$ & & 1 & 1 \\
\hline Without a spouse & $10(3.1)$ & $8(80.0)$ & $2(20.0)$ & & $1.31(0.27-6.35)$ & $0.69(0.11-4.31)$ \\
\hline No answer & 1 & & & & & \\
\hline Smoking & & & & 0.15 & & \\
\hline$<5$ packs & $196(60.9)$ & 169 (86.2) & $27(13.8)$ & & 1 & 1 \\
\hline$\geq 5$ packs & $126(39.1)$ & $101(80.2)$ & $25(19.8)$ & & $1.55(0.85-2.82)$ & $2.35(0.89-6.16)$ \\
\hline No answer & 1 & & & & & \\
\hline Alcohol & & & & 0.82 & & \\
\hline Non-drinking & $143(44.3)$ & $122(85.3)$ & $21(14.7)$ & & 1 & 1 \\
\hline Ex-drinking & $24(7.4)$ & $20(83.3)$ & $4(16.7)$ & & $1.17(0.36-3.74)$ & $1.53(0.43-5.49)$ \\
\hline Drinking & $156(48.3)$ & $129(82.7)$ & $27(17.3)$ & & $1.22(0.65-2.26)$ & $1.11(0.53-2.31)$ \\
\hline Regular exercise & & & & 0.80 & & \\
\hline Yes & $60(19.1)$ & $51(83.7)$ & $9(16.3)$ & & 1 & 1 \\
\hline No & 263 (80.9) & $220(85.0)$ & $43(15.0)$ & & $1.11(0.51-2.42)$ & $1.19(0.54-2.64)$ \\
\hline The average sleeping time in the last year & & & & 0.34 & & \\
\hline$\geq 7$ hours & $175(54.2)$ & $150(85.7)$ & $25(14.3)$ & & 1 & 1 \\
\hline$<7$ hours & $148(45.8)$ & $121(81.8)$ & $27(18.2)$ & & $1.34(0.74-2.43)$ & $1.45(0.78-2.69)$ \\
\hline
\end{tabular}

Values are expressed as unweighted counts and estimated percentages number (\%).

OR: odds ratio; $\mathrm{Cl}$ : confidence interval; SD: standard deviation.

${ }^{a}$ Adjusted for gender, age, educational status, smoking, and drinking status.

poisoning by cultivation of other crops than fruit trees did not show a statistically significant difference. By area of fruit farming in the total farm area, the participants were divided into 3 groups to analyze the prevalence of acute occupational pesticide poisoning, and the group with larger than $2,400 \mathrm{~m}^{2}$ area of fruit farming had the highest prevalence $(28.6 \%)$ of acute occupational pesticide poisoning. The results showed that the group with a larger fruit farm area had a higher prevalence of acute occupational pesticide poisoning, which was statistically significant $(p<0.05)$. According to a t-test analysis, the area of fruit farming of the group whose members experienced acute occupational pesticide poisoning was 20,779 \pm $12,246 \mathrm{~m}^{2}$, which is larger than that of the group $\left(16,605 \pm 11,409 \mathrm{~m}^{2}\right)$ whose members didn't experience it, and this was statistically significant $(p<0.01)$.

\section{Comparison of the prevalence of acute occupational pesticide poisoning by type of work using pesticides}

Table 4 shows the results of an analysis of the prevalence of acute occupational pesticide poisoning by type of work using pesticides. 
Table 3. The prevalence of acute occupational pesticide poisoning by characteristics of agricultural environment

\begin{tabular}{|c|c|c|c|c|c|c|}
\hline \multirow[t]{2}{*}{ Variables } & \multirow[t]{2}{*}{ Total } & \multicolumn{2}{|c|}{ Acute pesticide poisoning } & \multirow[t]{2}{*}{$p$-value } & \multirow{2}{*}{$\begin{array}{l}\text { Crude OR } \\
(95 \% \mathrm{Cl})\end{array}$} & \multirow{2}{*}{$\begin{array}{l}\text { Adjusted OR }{ }^{\mathrm{a}} \\
\quad(95 \% \mathrm{Cl})\end{array}$} \\
\hline & & No & Yes & & & \\
\hline The period of farming (years) & & & & 0.06 & & \\
\hline$\geq 40$ & $126(39.1)$ & $110(87.3)$ & $16(12.7)$ & & 1 & 1 \\
\hline $20-39$ & $149(46.3)$ & $126(84.6)$ & $23(15.4)$ & & $1.26(0.63-2.50)$ & $0.73(0.33-1.61)$ \\
\hline$<20$ & $47(14.6)$ & $34(72.3)$ & $13(27.7)$ & & $2.63(1.15-6.01)$ & $1.32(0.47-3.71)$ \\
\hline No answer & 1 & & & & & \\
\hline The cultivation of crops and fruits & & & & 0.50 & & \\
\hline Yes & $47(14.6)$ & $41(87.2)$ & $6(12.8)$ & & 1 & 1 \\
\hline No & $276(85.4)$ & $230(83.3)$ & 46 (16.7) & & $1.47(0.58-3.78)$ & $1.37(0.55-3.41)$ \\
\hline \multicolumn{7}{|l|}{ Total farm area $\left(\mathrm{m}^{2}\right)$} \\
\hline Mean \pm SD & $19,757 \pm 13,761$ & $18,662 \pm 12,690$ & $25,464 \pm 17,422$ & 0.00 & & \\
\hline$<12,000$ & $102(31.6)$ & $92(90.2)$ & $10(9.8)$ & 0.01 & 1 & 1 \\
\hline $12,000-23,999$ & $144(44.6)$ & $122(84.7)$ & $22(15.3)$ & & $1.66(0.75-3.67)$ & $1.34(0.59-3.04)$ \\
\hline$\geq 24,000$ & $77(23.8)$ & $57(74.0)$ & $20(26.0)$ & & $3.23(1.41-7.39)$ & $2.52(1.06-5.96)$ \\
\hline \multicolumn{7}{|l|}{ The area of fruit farming $\left(\mathrm{m}^{2}\right)$} \\
\hline Mean \pm SD & $17,277 \pm 11,630$ & $16,605 \pm 11,409$ & $20,779 \pm 12,246$ & 0.01 & & \\
\hline$<12,000$ & $127(39.3)$ & $113(89.0)$ & $14(11.0)$ & 0.01 & 1 & 1 \\
\hline $12,000-23,999$ & $140(43.3)$ & $118(84.3)$ & $22(15.7)$ & & $1.51(0.73-3.09)$ & $1.36(0.65-2.83)$ \\
\hline$\geq 24,000$ & $56(17.3)$ & $40(71.4)$ & $16(28.6)$ & & $3.23(1.45-7.21)$ & $2.65(1.16-6.08)$ \\
\hline
\end{tabular}

Values are expressed as unweighted counts and estimated percentages number (\%)

OR: odds ratio; $\mathrm{Cl}$ : confidence interval; SD: standard deviation.

${ }^{a}$ Adjusted for gender, age, educational status, smoking, and drinking status.

Table 4. The prevalence of acute occupational pesticide poisoning by type of work using pesticides

\begin{tabular}{|c|c|c|c|c|c|c|}
\hline \multirow[t]{2}{*}{ Variables } & \multirow[t]{2}{*}{ Total } & \multicolumn{2}{|c|}{ Acute pesticide poisoning } & \multirow[t]{2}{*}{$p$-value } & \multirow{2}{*}{$\begin{array}{c}\text { Crude OR } \\
(95 \% \mathrm{Cl})\end{array}$} & \multirow{2}{*}{$\begin{array}{l}\text { Adjusted OR }{ }^{\mathrm{a}} \\
\quad(95 \% \mathrm{Cl})\end{array}$} \\
\hline & & No & Yes & & & \\
\hline Role in spraying pesticide & & & & 0.98 & & \\
\hline None & $50(15.5)$ & $42(84.0)$ & $8(16.0)$ & & 1 & 1 \\
\hline Assistance & $59(18.3)$ & $49(83.1)$ & $10(16.9)$ & & $1.07(0.39-2.96)$ & $1.16(0.41-3.25)$ \\
\hline Main & $214(66.3)$ & $180(84.1)$ & $34(15.9)$ & & $0.99(0.43-2.30)$ & $1.74(0.42-7.22)$ \\
\hline Frequency of spraying pesticide (No. of times/years) & & & & 0.53 & & \\
\hline$\geq 20$ & $106(32.8)$ & $91(85.8)$ & $15(14.2)$ & & 1 & 1 \\
\hline$<20$ & $217(67.2)$ & $180(82.9)$ & $37(17.1)$ & & $1.25(0.65-2.39)$ & $1.38(0.70-2.72)$ \\
\hline Speed sprayer's cabin existence & & & & 0.55 & & \\
\hline Cabin-style speed sprayer & $79(24.5)$ & $68(86.1)$ & $11(13.9)$ & & 1 & 1 \\
\hline Cabinless-style speed sprayer & $244(75.5)$ & $203(83.2)$ & $41(16.8)$ & & $1.25(0.61-2.57)$ & $1.35(0.64-2.85)$ \\
\hline \multicolumn{7}{|l|}{ No. of PPE worn while spraying pesticide ${ }^{b}$} \\
\hline Mean \pm SD & $3.1 \pm 2.4$ & $3.2 \pm 2.4$ & $2.4 \pm 2.4$ & & & \\
\hline $4-7$ & $159(50.3)$ & $141(88.7)$ & $18(11.3)$ & 0.02 & 1 & 1 \\
\hline $0-3$ & $157(49.7)$ & $124(79.0)$ & $33(21.0)$ & & $2.10(1.13-3.91)$ & $2.15(1.09-4.24)$ \\
\hline No answer & 7 & & & & & \\
\hline
\end{tabular}

Values are expressed as unweighted counts and estimated percentages number (\%).

OR: odds ratio; $\mathrm{Cl}$ : confidence interval; SD: standard deviation; PPE: personal protective equipment.

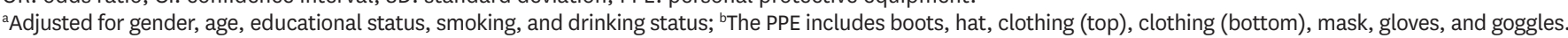

There were 7 pesticide PPE worn by farmers while spraying pesticides (goggles, hat, boots, gloves, mask, clothing [top], and clothing [bottom]), and the average number of PPE worn by the study participants was $3.1 \pm 2.4$. According to the prevalence of acute occupational pesticide poisoning by number of PPE, the group wearing 3 or less PPE while spraying pesticides had the risk of acute occupational pesticide poisoning by 2.15 times $(95 \%$ confidence interval: 1.09-4.24) higher than the group wearing 4 or more PPE, which was statistically significant $(p<0.05)$.

However, the prevalence of acute occupational pesticide poisoning by role in spraying pesticides, frequency of spraying pesticides per year, and method of spraying pesticides showed no statistically significant difference. 


\section{Prevalence of acute occupational pesticide poisoning by speed sprayer's} cabin existence among main sprayers

Table 5 shows the prevalence of acute occupational pesticide poisoning by speed sprayer's cabin existence among main sprayers. The speed sprayer's cabin existence is presented in Fig. 2. According to the observations of pesticide spray practices in this survey, it was conjectured that cabin-style speed sprayers would produce less dermal exposure during pesticide spray than cabinless-style speed sprayers. However, an analysis of the prevalence of acute occupational pesticide poisoning by speed sprayer's cabin existence did not show a statistically significant difference.

Table 6 shows the average number of PPE worn by speed sprayer's cabin existence among main sprayers and the percentage of wearing PPE by type of PPE. The average number of PPE worn by main sprayers using the cabinless-style speed sprayer was $4.4 \pm 1.8$, which was higher than $2.0 \pm 2.1$, the average number of PPE worn by those using the cabin-style speed sprayer $(p<0.01)$. Those using the cabinless-style speed sprayer showed a higher percentage of wearing 5 PPE (hat, boots, mask, clothing [top], and clothing [bottom]) except for gloves and goggles than those using the cabin-style speed sprayer, which was statistically significant $(p<0.05)$.

\section{DISCUSSION}

In the present study, orchard farmers' prevalence of acute occupational pesticide poisoning symptoms was $16.1 \%$. The average number of multiple responses for acute occupational pesticide poisoning symptoms was $1.7 \pm 1.5$. A previous study on Korean male farmers in 2011 reported the prevalence of acute occupational pesticide poisoning as $22.9 \%$, and compared to its finding that the prevalence of acute occupational pesticide poisoning among orchard farmers was $31.5 \%$, the present study's prevalence was lower than the previous

Table 5. Prevalence of acute occupational pesticide poisoning by speed sprayer's cabin existence among main sprayers $(n=214)$

\begin{tabular}{lccrc}
\hline Speed sprayer's cabin existence & Total & \multicolumn{2}{c}{ Acute pesticide poisoning } & \multirow{2}{*}{$p$-value } \\
\cline { 3 - 4 } & & No & Yes & 0.91 \\
\hline Cabin-style speed sprayer & $52(24.3)$ & $44(84.6)$ & $8(15.4)$ & \\
Cabinless-style speed sprayer & $162(75.7)$ & $136(84.0)$ & $26(16.0)$ & \\
\hline
\end{tabular}

Values are expressed as unweighted counts and estimated percentages number (\%).
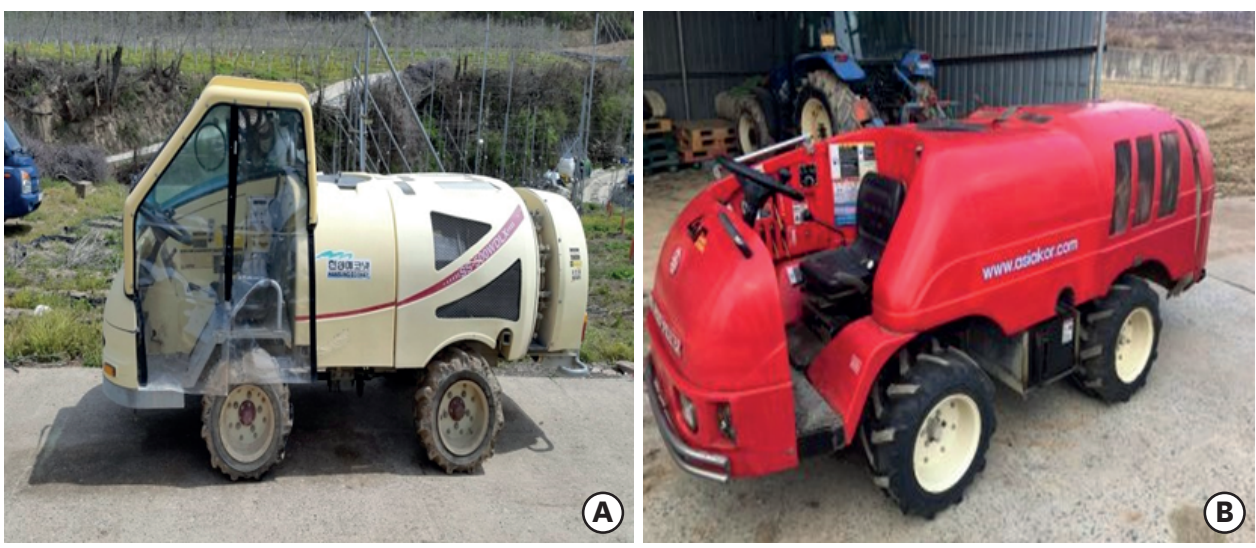

Fig. 2. (A) A cabin-style speed sprayer. (B) A cabinless-style speed sprayer. 


\begin{tabular}{|c|c|c|c|c|}
\hline \multirow[t]{2}{*}{ Variables } & \multirow[t]{2}{*}{ Total } & \multicolumn{2}{|c|}{ Speed sprayer's cabin existence } & \multirow[t]{2}{*}{$p$-value } \\
\hline & & No & Yes & \\
\hline The average No. of PPE ${ }^{a}$ & $3.8 \pm 2.2$ & $4.4 \pm 1.8$ & $2.0 \pm 2.1$ & \\
\hline Boots & & & & 0.00 \\
\hline Always & $148(69.2)$ & $128(79.0)$ & $20(38.5)$ & \\
\hline Not always & $66(30.8)$ & $34(21.0)$ & $32(61.5)$ & \\
\hline Hat & & & & 0.00 \\
\hline Always & $142(66.4)$ & $122(75.3)$ & $20(38.5)$ & \\
\hline Not always & $72(33.6)$ & $40(24.7)$ & $32(61.5)$ & \\
\hline Clothing (top) & & & & 0.00 \\
\hline Always & $140(65.4)$ & 132 (81.5) & $8(15.4)$ & \\
\hline Not always & $74(34.6)$ & $30(18.5)$ & $44(84.6)$ & \\
\hline Clothing (bottom) & & & & 0.00 \\
\hline Always & $137(64.0)$ & $129(79.6)$ & $8(15.4)$ & \\
\hline Not always & 77 (36.0) & $33(20.4)$ & $44(84.6)$ & \\
\hline Mask & & & & 0.02 \\
\hline Always & $117(54.7)$ & $96(59.3)$ & $21(40.4)$ & \\
\hline Not always & $97(45.3)$ & 66 (40.7) & 31 (59.6) & \\
\hline Gloves & & & & 0.42 \\
\hline Always & $101(47.2)$ & $79(48.8)$ & $22(42.3)$ & \\
\hline Not always & $113(52.8)$ & $83(51.2)$ & $30(57.7)$ & \\
\hline Goggles & & & & 0.49 \\
\hline Always & $31(14.5)$ & $25(15.4)$ & $6(11.5)$ & \\
\hline Not always & $183(85.5)$ & $137(84.6)$ & $46(88.5)$ & \\
\hline
\end{tabular}

Values are expressed as unweighted counts and estimated percentages number (\%) or mean \pm standard deviation. PPE: personal protective equipment.

aThe PPE includes boots, hat, clothing (top), clothing (bottom), mask, gloves, and goggles.

study's [35]. The reason the present study's prevalence was lower than the previous study's seems to be because interest in farming occupational diseases and health effects caused by pesticide poisoning is recently growing among farmers, and there have been changes towards low-pesticide and environmentally-friendly farming methods [37]. While the present study was conducted mostly on fruit farming in south Chungcheong Province, the previous study examined farmers across South Korea, which would have contributed to a difference with the present study [35]. A follow-up study would need to examine differences among specific fruit trees.

According to previous studies, a larger farm area led to a higher prevalence of acute occupational pesticide poisoning, and the reason has been reported that a larger farm area requires more pesticides to use $[26,33]$. Also, in the present study, the group with a larger area of fruit farming had a higher prevalence of acute occupational pesticide poisoning, which was statistically significant $(p<0.05)$.

A considerable amount of time is required for preparing before pesticide spray and wrapping up after pesticide spray. While diluting pesticides, preparing the sprayer, or wrapping up, pesticides could be absorbed into the skin when farmers come into contact with the sprayer contaminated by pesticides. The calculation of the pesticide exposure index used in general considers whether pesticides are diluted before spray or the cleaning and repair of the sprayer after pesticide spray [38]. Hence, to effectively prevent pesticide exposure, it is necessary to wear PPE from the preparation of pesticide spray to wrap-up after pesticide spray.

According to previous studies, wearing PPE overall decreased the prevalence of acute occupational pesticide poisoning, but the result was statistically significant in just some of those studies [35,39]. The previous studies divided wearing PPE into 'often' and 'always'. The 
average number of PPE was less than 3, and the percentage of wearing PPE was relatively low except for boots and hat, which imply PPE may not effectively prevent pesticide exposure in previous studies. According to another study that measured the level of pesticide exposure among farmers using speed sprayers, the level of respiratory pesticide exposure by the farmers using speed sprayers was $0.1 \%$ lower than that of dermal exposure, and the level of dermal pesticide exposure by part of the body was high in the order of thighs, shins, and chest/abdomen [40]. Therefore, wearing PPE is important to effectively prevent pesticide exposure among farmers using speed sprayers.

Compared to other crops, fruit trees require a larger farm area and are taller, and thus speed sprayers are used to spray pesticides. In the present study, it was found that $100 \%$ of the participants used speed sprayers. A previous study, which examined the prevalence of acute occupational pesticide poisoning by method of spraying pesticides, reported that the prevalence of farmers using speed sprayers was higher than that of those using high pressure hand sprayers, manual backpack sprayers, mist or hand sprayers, air sprayers and others [35]. However, no study looked into the prevalence of acute occupational pesticide poisoning depending on the speed sprayer's cabin existence. According to the observations of pesticide spray practices in this survey, working inside confined cabin when using a cabin-style speed sprayer would have protected them from pesticide exposure. In this context, the present study analyzed the prevalence of acute occupational pesticide poisoning by speed sprayer's cabin existence.

For those who spray pesticides mainly, the average number of PPE worn by farmers using the cabinless-style speed sprayer was $4.4 \pm 1.8$, which was higher than $2.0 \pm 2.1$, the number of PPE worn by farmers using the cabin-style speed sprayer, and the difference was statistically significant $(p<0.01)$. Farmers using the cabinless-style speed sprayer showed a higher percentage of wearing 5 PPE (hat, boots, mask, clothing [top], and clothing [bottom]) than those using the cabin-style speed sprayer, which was statistically significant $(p<0.05)$. In particular, farmers using the cabinless-style speed sprayer showed the percentage of wearing clothing (top) and clothing (bottom) more than 5 times that of those using the cabin-style speed sprayer. Since questionnaire items in the present study examined wearing PPE during pesticide spray, there was a limitation that they could not examine wearing PPE during the preparation and wrap-up of pesticide spray. However, farmers were more likely to wear PPE during the preparation and wrap-up of pesticide spray if they had worn PPE during pesticide spray. This survey's results showed no statistically significant difference in the prevalence of acute occupational pesticide poisoning by speed sprayer's cabin existence among those main pesticide sprayers. In other words, while using the cabin-style speed sprayer can prevent pesticide exposure during pesticide spray, it is required to wear PPE before and after spraying pesticides to prevent pesticide exposure more effectively.

The following are the limitations of the present study. First, there could have been recall bias as it was a questionnaire survey that asked farmers for the prevalence of acute occupational pesticide poisoning over the last 1 year. Second, it is difficult to generalize the results of this study to all farmers living in Korea. Participant in the present study were limited to orchard farmers in south Chungcheong Province. A follow-up study of examination by type of fruit tree may be required in not just south Chungcheong Province but a wider region. Third, since acute occupational pesticide poisoning symptoms were identified by the questionnaire, it did not examine biomarkers. Also, in this study, acute pesticide poisoning is not the clinical diagnosis of a physician in a medical institution. A follow-up study would need to use biomarkers and clinical diagnoses. Forth, the questionnaire used in this study was developed 
by referring to the questionnaire used in the implementation project of a safety model for agricultural work conducted by the Rural Development Administration in South Korea the question concerning symptoms of acute pesticide poisoning. However, there are limitations that do not provide a clear basis for the validity and reliability of the questionnaire used in this study. Despite such limitations, however, the present study has the following strengths. First, it used 3 years $(2014,2015$, and 2017) of questionnaire data. Second, while it was based on questionnaire data, it conducted one-on-one face-to-face interviews and is considered to have higher reliability than a survey that simply hands out questionnaire copies. Finally, it holds research significance as the first study in Korea that examined the prevalence of acute occupational pesticide poisoning by speed sprayer's cabin existence.

The present study shows the expected effect that wearing pesticide PPE along with using the speed sprayer's cabin can reduce the prevalence of acute occupational pesticide poisoning among orchard farmers.

\section{CONCLUSIONS}

The speed sprayer that orchard farmers use often for pesticide spray has the effect of preventing pesticide exposure during pesticide spray if it has a cabin. To prevent pesticide exposure before and after pesticide spray, however, it is indispensable to wear PPE. The present study analyzed the prevalence of acute occupational pesticide poisoning by speed sprayer's cabin existence when orchard farmers used the speed sprayer. The result was that although the group wearing few PPE among farmers using the cabin-style speed sprayer had a higher risk of acute occupational pesticide poisoning, the difference was not statistically significant. By contrast, the group wearing few PPE among farmers using the cabinlessstyle speed sprayer had a statistically significant higher risk of pesticide poisoning. Thus, it is important to not only use the speed sprayer's cabin but also increase the percentage of wearing PPE in order to reduce orchard farmers' pesticide exposure. In addition, the present study holds significance as the first study in Korea which examined the prevalence of acute occupational pesticide poisoning by speed sprayer's cabin existence.

\section{REFERENCES}

1. World Health Organization. Pesticides [Internet]. Geneva: World Health Organization; 2019. Available from: https://www.who.int/topics/pesticides/en/. Accessed 15 Feb 2019.

2. Engelhaupt E. Real-world pesticide mixtures harm salmon. Environ Sci Technol 2008;42(13):4619. PUBMED | CROSSREF

3. Linke B, Mohr S, Ramsingh D, Bhuller Y. A retrospective analysis of the added value of 1-year dog studies in pesticide human health risk assessments. Crit Rev Toxicol 2017;47(7):581-91. PUBMED | CROSSREF

4. Kumbhkar Y, Mehta HK, Bagherwa RK, Badsar P. Pesticide poisoning in a dog-a case report. Indian Vet J 2018;95(7):57-8.

5. Whitehorn PR, O'Connor S, Wackers FL, Goulson D. Neonicotinoid pesticide reduces bumble bee colony growth and queen production. Science 2012;336(6079):351-2. PUBMED | CROSSREF

6. Lee WJ. Pesticide exposure and health. J Environ Health Sci 2011;37(2):81-93.

7. Cimino AM, Boyles AL, Thayer KA, Perry MJ. Effects of neonicotinoid pesticide exposure on human health: a systematic review. Environ Health Perspect 2017;125(2):155-62.

PUBMED | CROSSREF 
8. Chiu BC, Dave BJ, Blair A, Gapstur SM, Zahm SH, Weisenburger DD. Agricultural pesticide use and risk of $\mathrm{t}(14 ; 18)$-defined subtypes of non-Hodgkin lymphoma. Blood 2006;108(4):1363-9. PUBMED | CROSSREF

9. Dennis LK, Lynch CF, Sandler DP, Alavanja MC. Pesticide use and cutaneous melanoma in pesticide applicators in the agricultural heath study. Environ Health Perspect 2010;118(6):812-7. PUBMED | CROSSREF

10. Kang D, Park SK, Beane-Freeman L, Lynch CF, Knott CE, Sandler DP, et al. Cancer incidence among pesticide applicators exposed to trifluralin in the agricultural health study. Environ Res 2008;107(2):271-6. PUBMED | CROSSREF

11. Koutros S, Beane Freeman LE, Lubin JH, Heltshe SL, Andreotti G, Barry KH, et al. Risk of total and aggressive prostate cancer and pesticide use in the agricultural health study. Am J Epidemiol 2013;177(1):59-74. PUBMED | CROSSREF

12. Park SK, Kang D, Beane-Freeman L, Blair A, Hoppin JA, Sandler DP, et al. Cancer incidence among paraquat exposed applicators in the agricultural health study: prospective cohort study. Int J Occup Environ Health 2009;15(3):274-81. PUBMED | CROSSREF

13. Presutti R, Harris SA, Kachuri L, Spinelli JJ, Pahwa M, Blair A, et al. Pesticide exposures and the risk of multiple myeloma in men: an analysis of the North American Pooled Project. Int J Cancer 2016;139(8):1703-14. PUBMED | CROSSREF

14. Abraham NF, Feldman SR, Vallejos Q, Whalley LE, Brooks T, Cabral G, et al. Contact dermatitis in tobacco farmworkers. Contact Dermat 2007;57(1):40-3. PUBMED | CROSSREF

15. Horiuchi N, Oguchi S, Nagami H, Nishigaki Y. Pesticide-related dermatitis in Saku district, Japan, 1975-2000. Int J Occup Environ Health 2008;14(1):25-34. PUBMED | CROSSREF

16. Irby CE, Yentzer BA, Vallejos QM, Arcury TA, Quandt SA, Feldman SR. The prevalence and possible causes of contact dermatitis in farmworkers. Int J Dermatol 2009;48(11):1166-70. PUBMED | CROSSREF

17. Meyer A, Sandler DP, Beane Freeman LE, Hofmann JN, Parks CG. Pesticide exposure and risk of rheumatoid arthritis among licensed male pesticide applicators in the agricultural health study. Environ Health Perspect 2017;125(7):077010. PUBMED | CROSSREF

18. Beard JD, Umbach DM, Hoppin JA, Richards M, Alavanja MC, Blair A, et al. Suicide and pesticide use among pesticide applicators and their spouses in the agricultural health study. Environ Health Perspect 2011;119(11):1610-5. PUBMED | CROSSREF

19. Beard JD, Umbach DM, Hoppin JA, Richards M, Alavanja MC, Blair A, et al. Pesticide exposure and depression among male private pesticide applicators in the agricultural health study. Environ Health Perspect 2014;122(9):984-91. PUBMED | CROSSREF

20. Berry C, La Vecchia C, Nicotera P. Paraquat and Parkinson's disease. Cell Death Differ 2010;17(7):1115-25. PUBMED | CROSSREF

21. Starks SE, Hoppin JA, Kamel F, Lynch CF, Jones MP, Alavanja MC, et al. Peripheral nervous system function and organophosphate pesticide use among licensed pesticide applicators in the agricultural health study. Environ Health Perspect 2012;120(4):515-20. PUBMED | CROSSREF

22. Kirrane EF, Hoppin JA, Kamel F, Umbach DM, Boyes WK, Deroos AJ, et al. Retinal degeneration and other eye disorders in wives of farmer pesticide applicators enrolled in the agricultural health study. Am J Epidemiol 2005;161(11):1020-9. PUBMED | CROSSREF

23. Son HK, Kim SA, Kang JH, Chang YS, Park SK, Lee SK, et al. Strong associations between low-dose organochlorine pesticides and type 2 diabetes in Korea. Environ Int 2010;36(5):410-4. PUBMED | CROSSREF

24. Park S, Kim SK, Kim JY, Lee K, Choi JR, Chang SJ, et al. Exposure to pesticides and the prevalence of diabetes in a rural population in Korea. Neurotoxicology 2019;70:12-8. PUBMED | CROSSREF 
25. Korean Statistical Information Service. The characteristics of farm family by type of farming 2017 [Internet]. Daejeon: Korean Statistical Information Service; 2019. Available from: http://kosis.kr/ statHtml/statHtml.do?orgId=101\&tblId=DT_1EA1018\&conn_path=I2. Accessed 15 Feb 2019.

26. Ha HY, Ra DS, Shin WC, Im GJ, Park JE. Survey of pesticide use in fruit vegetables, fruits, and rice cultivation areas in Korea. Korean J Pestic Sci 2012;16(4):395-400. CROSSREF

27. Lee KM, Min SY, Chung MH. A study on the health effects of pesticide exposure among farmers. Korean J Rural Med 2000;25(2):245-63.

28. Cha ES, Khang YH, Lee WJ. Mortality from and incidence of pesticide poisoning in South Korea: findings from National Death and Health Utilization Data between 2006 and 2010. PLoS One 2014;9(4):e95299. PUBMED | CROSSREF

29. Ko Y, Kim HJ, Cha ES, Kim J, Lee WJ. Emergency department visits due to pesticide poisoning in South Korea, 2006-2009. Clin Toxicol (Phila) 2012;50(2):114-9. PUBMED | CROSSREF

30. Lee WJ, Cha ES. Overview of pesticide poisoning in South Korea. J Rural Med 2009;4(2):53-8. CROSSREF

31. Kim E, Moon JK, Lee H, Kim S, Hwang YJ, Kim BJ, et al. Exposure and risk assessment of operators to insecticide acetamiprid during treatment on apple orchard. Korean J Hort Sci Technol 2013;31(2):239-45. CROSSREF

32. World Health Organization. Acute pesticide poisoning: a proposed classification tool [Internet]. Geneva: World Health Organization; 2008. Available from: https://www.who.int/bulletin/volumes/86/3/07-041814/ en/. Accessed 18 Feb 2019.

33. Kim HJ, Cha ES, Moon EK, Ko Y, Kim J, Jeong M, et al. A pilot study for pesticide poisoning symptoms and information on pesticide use among farmers. J Environ Health Sci 2011;37(1):22-8. CROSSREF

34. Lee WJ, Cha ES, Park J, Ko Y, Kim HJ, Kim J. Incidence of acute occupational pesticide poisoning among male farmers in South Korea. Am J Ind Med 2012;55(9):799-807. PUBMED | CROSSREF

35. Kim JH, Kim J, Cha ES, Ko Y, Kim DH, Lee WJ. Work-related risk factors by severity for acute pesticide poisoning among male farmers in South Korea. Int J Environ Res Public Health 2013;10(3):1100-12. PUBMED | CROSSREF

36. World Health Organization. Adverse health effects caused by selected classes of pesticides Table 1 [Internet]. Geneva: World Health Organization; 2008. Available from: https://www.who.int/bulletin/ volumes/86/3/07-041814-table-T1.html. Accessed Day Month Year.

37. Korean Statistical Information Service. Pesticide sales from 2006 to 2016 [Internet]. Daejeon: Korean Statistical Information Service; 2019. Available from: http://kosis.kr/statHtml/statHtml. do?orgId=101\&tblId=DT_1EA1018\&conn_path=I2. Accessed 25 Feb 2019.

38. Dosemeci M, Alavanja MC, Rowland AS, Mage D, Zahm SH, Rothman N, et al. A quantitative approach for estimating exposure to pesticides in the agricultural health study. Ann Occup Hyg 2002;46(2):245-60. PUBMED

39. Lee HS, Lee JH, Roh SY, Kim HG, Lee KJ, Nam-Gung SJ, et al. Symptom prevalence and work-related risk factors of acute pesticide poisoning among Korean farmers in Gyeong-gi province. J Agric Med Community Health 2015;40(4):228-39. CROSSREF

40. Kim E, Moon JK, Choi H, Kim JH. Probabilistic exposure assessment for applicators during treatment of the fungicide kresoxim-methyl on an apple orchard by a speed sprayer. J Agric Food Chem 2015;63(48):10366-71. PUBMED | CROSSREF 